HARRIS, M. (1998) Continuous professional development for psychiatrists. Psychiatric Bulletin, 22, 67-68.

KENDEL, R. E. \& PEARCE, A. (1997) Consultant psychiatrists who retired prematurely in 1995 and 1996. Psychiatric Bulletin, 21, 741-745.

WiunMs, C. J., SiMS, A. C. P. \& SENSKY, T. (1998) Consultant psychlatrists' opinions and experience of CPD. Psychiatric Bulletin, 22, 348-350.
David Newby, Deputy Regional Adviser for CPD. Yorkshire and Coordinator for CPD, Leeds Community \& Mental Health Teaching Trust, Millfield House, Kirk Lane, Yeadon, Leeds LS19 7LX

\title{
Higher psychiatric trainees and the Calman reforms
}

\author{
Paul Cavanagh and Fabian Haut
}

\begin{abstract}
Alms and method The specialist registrar (SPR) grade was introduced in 1996. taking the place of the senior registrar (SR) grade. We surveyed higher trainees in scotland in order to draw comparisons between the two grades and assess satisfaction with the changes. A postal questionnaire was sent to all higher trainees $(n=129)$ in Scotland seoking information on structure of training, work patterns and views.

Reeults Sixty-two per cent of trainees responded. There was little difference in the activity and structure of training between SRs and SpRs. Seventy per cent of responders felt that the SpR grade had not improved training.
\end{abstract}

Clinical implications the survey uncovered dissatisfaction with the new grade, but little objective evidence of differences between SRs and SpRs. More flexibility for time in higher training and restoring the $S R$ ttile would help to improve morale.

In 1996 the first wave of specialist registrars (SpR), the new higher training grade, took up posts in Scotland. The grade was introduced following the publication of the report of the working group on specialist medical training by the Department of Health in 1993 - the Calman report (Department of Health, 1993). Protracted discussions between the various Royal Colleges and professional bodies concerning implementation followed, particularly in the context of earlier Department of Health work on medical manpower (Department of Health, 1987). The working groups had been set up as a response to Britain's requirement to fall in line with the
European Commission's directives on specialist recognition. However other factors played a part: the need to reduce junior doctors hours as a consequence of the New Deal (NHS Management Executive, 1991); concern often arising from clinical audit of excessive reliance on junior doctors to provide services and a desire to move to a consultant led service (Department of Health, 1987), and a sense that specialists were spending too long unproductively in training (Hunter \& McLaren, 1993).

The Calman report stimulated much debate on the likely implications for consultants and trainees (Charlton, 1993; Ross, 1993; Mather \& Elkeles, 1996). Possibilities envisaged were that consultants would do more emergency work and trainees would be largely supernumerary, or that a junior consultant grade would need to be developed (Charlton, 1993). There was controversy over interpretation of the European Commission directives and manpower plans set out in achieving a balance (Brearley, 1992; Ross, 1993). exposed differences in opinion regarding what training should be expected of specialists in the UK and what the nature of consultant work should be (Johnson, 1995). In contrast to other clinical specialities where the registrar and SR grades were merged, the Royal College of Psychiatrists chose to use the $\mathrm{SpR}$ grade to replace the senior registrar (SR) grade and merge the senior house officer (SHO) and registrar grades, using the MRCPsych Examination as entry into higher training (Caldicott, 1993). We thought it timely, after 18 months as SpRs, to survey the 
views of our colleagues in Scotland regarding the changes. Professor Calman's intention had been that the reforms would "put training at the top of the agenda" (Smith, 1994). Professor Kendell, then Scotland's Chief Medical Officer, had expressed his hope that the new grade in Scotland would lead to shorter and more structured training (Kendell, 1995). We aimed to discover how far those objectives were being met by comparing the lot of SRs and SpRs.

\section{Method}

A postal questionnaire was designed in order to gather information concerning personal data, structure of training and attitudes to the changes. Access to regular supervision, ability to take research and special interest sessions, and freedom to influence training were chosen to reflect structure of training.

Attitudes were tested by asking what respondents liked and what they disliked about the system, and what changes they would make if given a free hand. The questionnaire was tested for acceptability locally before being distributed to all higher trainees in Scotland via the chair of the higher trainees group in each of the four Scottish Regions: Northern, Eastern, SouthEastern and Western. The period of the study was March 1998, and the questionnaire was accompanied by a covering letter explaining its purpose and guaranteeing anonymity. Chairs of higher trainee groups were asked to issue reminders after six weeks, and all completed forms were received for analysis by the end of May 1998.

\section{Results}

\section{Personal information}

Eighty responses were received, out of a total of 129 potential respondents, a response rate of $62 \%$. The mean age of the respondents was 34.2 years (median 33, range 28-50) and mean length of time in higher training was 24 months (median 20. range 0-72). Thirty-four (42.5\%) of the respondents were SRs and $45(56.2 \%)$ were SpRs. The mean length of time post-RCPsych Membership Examination was three years four months.

\section{Research and special interest sessions}

Twelve per cent of SRs and 22\% of SpRs are not able to take two research sessions per week. Thirty-five per cent of SRs and 38\% of SpRs were unable to take special interest sessions on a regular basis. The most common reason given was that it was not allowed or expected and pressure of work did not allow for it. Only $49 \%$ of
SRs and $67 \%$ of SpRs were in receipt of regular weekly supervision, with $16 \%$ of SRs and $7 \%$ of SpRs recetving supervision less than once per month.

\section{Duties}

Respondents were asked if the nature of their work differed to that of basic grade trainees. No differences were evident between SRs and SpRs in this regard, but one-fifth of each group were expected to carry out similar out of hours duties to SHOs.

\section{Training plan}

Twenty-six per cent of all trainees felt unable to freely plan their training, and there were no differences in this regard between SRs and SpRs. The most common reason for difficulties in planning training was primacy of service commitments, although availability of posts and dictatorial tutors also featured as reasons.

\section{Attitudes to changes in training}

Only five (6\%) respondents felt that the introduction of the SpR grade had improved higher training, with $56(70 \%)$ feeling that it had not and $19(24 \%)$ unable to express an opinion. On the positive side training was seen as more streamlined, but shortened training, limited training choices and experience, too great a service commitment, insufficient gain to justify the upheaval and loss of status and autonomy were the principal opposing views.

Almost all of $(97 \%)$ SRs and $73 \%$ of the SpRs would chose the SR grade, with only two respondents choosing to be SpRs.

Positive aspects of the changes were felt to be better structure and organisation of training including clearer training objectives, formal reviews, and a belief that numbers of trainees were tailored to fit future consultant vacancies. The principal negative comments were, in descending order of frequency:

(a) Shorter/inadequate time in training.

(b) Less distinction in work between basic and higher training grades and, in particular, taking on duties previously carried out by basic grade trainees.

(c) Training, including length of time in training, inflexible.

(d) Loss of status.

(e) Increased bureaucracy.

(f) Less opportunity for sub-speciality experience. 
What changes would trainees make, given a free hand?

Themes which emerged most frequently were:

(a) Making time in higher training flexible (usually longer).

(b) Return to SR title.

(c) Introduction of formal training plans, management and research training, and formal teaching.

(d) Greater flexdbility to allow sub-speciality training.

(e) Make clear difference in duties between basic and higher grade trainees.

\section{Discussion}

The principal objectives behind the introduction of the SpR grade were to put training at the top of the agenda (Smith, 1994), to meet European Community directives on specialist recognition and to achieve shorter and more structured training (Kendell, 1995). Respondents felt that rather than raising the profile of training, the changes served as an opportunity for trusts to increase the service commitment of training posts. A perceived loss of training opportunities and flexibility in making choices has added to the sense of constraint. It may be that for manpower purposes foreshortened training will help to fill the gap in the short-term. However, it is possible that the long-term price for this is inadequately trained specialists. It is a matter of concern that formal supervision appears to be patchy. The College expects trainees to have weekly supervision, but half of all SRs do not and as many as $16 \%$ receive supervision less than once a month. Interestingly, this is one area where SpRs do better, but a significant number are seriously undersupervised. SpRs, however, were less likely to be able to take two research sessions than their SR colleagues, a circumstance that is surprising given the sense of better planning and structuring of training. As the absolute numbers of trainees taking part in the survey are small, it would perhaps be wise not to draw too firm conclusions on the differences between the grades. Findings on supervision are similar to an earlier survey carried out in 1992 (Beats et al, 1992).

The reported differences in this survey between SR and SpR grades are not great, so why the unpopularity of the new grade? It seems that there are three principal reasons - a perceived loss of status, concerns about lack of flexibility and too short a time in higher training. Three years in higher training may well be enough for many; it is clear for some that it is not - although it should be noted that basic grade trainees may have different views on this matter than higher trainees (Evans \& Johnson, 1994). The European directive on specialist training does not specify a proposed or equivalent length of training, and therefore there is no external pressure for training to be curtailed (Brearley, 1992) - why not a defined minimum, with the individual trainee, together with speciality tutors, deciding what the content of their training should be, and letting this define the time spent in training?

Tension between service and training needs is not new, and it may well be the case that similar views would have been expressed if this survey had been carried out 10 years ago. It may be that higher trainees are feeling the effects of increased pressure on seniors time-either through a trickle down effect of increased work or simply vicarious stress at ever increasing workloads and a realisation that, professionally, higher trainees have the opportunity to have the best days of their lives' and do not want them spoiled.

This survey has not demonstrated any differences between the nature of training for SRs or SpRs, but has exposed areas of real concern to trainees concerning their training opportunities and morale. A worrying number of trainees are undersupervised, and some find difficulty in planning their training, and in gaining time to research or follow specialist areas of interest. In addition, there have been a number of positive suggestions regarding how training could be structured better. Introducing greater flexdbility in allowing trainees to tailor time in training to perceived individual needs and a change of title from SpR back to SR would go a long way towards improving morale.

\section{References}

Beats, B., BAGLEY, G., BANKS, V., et al (1992) Higher training in old age psychiatry: a survey of senior registrars' experience. Psychiatric Bulletin, 16, 622624.

BREARLEY, S. (1992) Specialist medical training and the European Community. British Medical Joumal. $\mathbf{3 0 8 .}$ 661-662.

CALDICOTT, F. (1993) Response to the Chief Medical Officer's Report on Specialist Training. Psychiatric Bullettin, 17. 577-579.

Calman, K. (1994) The profession of medicine. British Medical Journal, 309. 1140-1143.

ChARLTON, B. G. (1993) Service implications of the Calman report. British Medical Joumal, 307. 338-339.

Evans, M. \& Johnson C. (1994) The Calman report: does training matter to trainees? Psychiatric Bulletin, 18 . 405-407.

DEPARTMENT OF HEALTH (1987) Hospital Medical Staffing: Achieving a Balance. Plan For Action. London: Department of Health

- (1993) Hospital Doctors: Training for the Future. The Report of the Working Group on Specialist Medical Training. London: Department of Health. 
Hunter, S. \& MCLAREN, P. (1993) Specialist medical training and the Calman report. British Medical Journal, $\mathbf{3 0 6}$ 1281-1282.

JoHNSON, J. N. (1995) Survey lllustrates misconception of the Calman proposals. British Medical Joumal, 311. 1298.

KENDELL, R. E. (1995) Implementing the Reforms to Specialist Medical Training. CMA11710. Edinburgh: Department of Health \& The Scottish Office.

MATHER, H. M. \& ElkEles, R. S. (1996) Attitude of consultant physiclans to Calman proposals. British Medical Joumal, $312,443$.

NHS MANAGEMENT EXECUTIVE (1991) Junior Doctors: the New Deal. London: NHS Management Executtve.
Ross, A. P. J. (1993) The Calman report: service implications uncertain. British Medical Journal, 807. 628.

SMrTH, R. (1994) Challenging doctors: an interview with England's chief medical officer. British Medical Journal. S08, 1221-1224.

*Paul Cavanagh, Specialist Registrar, and Fabian Haut, Specialist Registrar, Teaching and Research Division, Royal Dundee Liff Hospital, Dundee DD2 5NF

*Correspondence

\section{How to Teach Critical Review Skills}

\section{4 - 5 November, 1999, Weetwood Hall, Leeds}

This course will equip psychiatrists of all grades with the knowledge, understanding and skills to undertake critical appraisal of the published literature. It will also refresh knowledge and develop skills and attitudes necessary for teaching critical review for the MRCPsych Part II critical review paper. The course will be especially valuable for those wishing to acquire or refresh critical appraisal skills for life long learning, clinical psychiatric practice and for assessing evidence-based material.

\section{Topics covered}

- Does the design answer the research question?

- $\quad$ Sampling and setting

- Are the measures good enough?

- The use of statistics to assess the truth of main findings

- How to review a review

\section{CPD Validation Units 9}

Cost: $£ 180$ (inclusive of $B \& B$ accommodation, three course dinner, 2 course carvery lunch, tea and coffee during the course).

For an application form please contact: Mr Noel Bell, Royal College of Psychiatrists, 17 Belgrave Square, London, SW1X 8PG, Tel: 01712352351 ext 157 email: nbell@rcpsych.ac.uk 